\title{
GABAergic Input Affects Intracellular Calcium Levels in Developing Granule Cells of Adult Rat Hippocampus
}

\author{
Davide Lattanzi, Michael Di Palma, Riccardo Cuppini ${ }^{\mathbb{D}}$ and Patrizia Ambrogini *D \\ Department of Biomolecular Sciences, University of Urbino Carlo Bo, I-61029 Urbino, Italy; \\ davide.lattanzi@uniurb.it (D.L.); michael.dipalma@uniurb.it (M.D.P.); riccardo.cuppini@uniurb.it (R.C.) \\ * Correspondence: patrizia.ambrogini@uniurb.it; Tel.: +39 0722304292
}

Received: 7 February 2020; Accepted: 2 March 2020; Published: 3 March 2020

check for updates

\begin{abstract}
In the dentate gyrus (DG) of the mammalian hippocampus, granule neurons are generated from neural stem cells (NSCs) throughout the life span and are integrated into the hippocampal network. Adult DG neurogenesis is regulated by multiple intrinsic and extrinsic factors that control NSC proliferation, maintenance, and differentiation into mature neurons. $\gamma$-Aminobutyric acid (GABA), released by local interneurons, regulates the development of neurons born in adulthood by activating extrasynaptic and synaptic $\mathrm{GABA}_{\mathrm{A}}$ receptors. In the present work, patch-clamp and calcium imaging techniques were used to record very immature granule cells of adult rat dentate gyrus for investigating the actual role of $\mathrm{GABA}_{\mathrm{A}}$ receptor activation in intracellular calcium level regulation at an early stage of maturation. Our findings highlight a novel molecular and electrophysiological mechanism, involving calcium-activated potassium channels (BK) and T-type voltage-dependent calcium channels, through which GABA fine-tunes intracellular calcium homeostasis in rat adult-born granule neurons early during their maturation. This mechanism might be instrumental in promoting newborn cell survival.
\end{abstract}

Keywords: adult rat; GABA input; T-type voltage-dependent calcium channels; calcium-activated potassium channels; hippocampus; immature neurons; membrane potential oscillations

\section{Introduction}

The hippocampus dentate gyrus (DG) subgranular zone (SGZ) represents one of the neurogenic niches where radial glia-like neural stem cells (NSCs) continuously generate new neurons throughout adulthood. This process, known as adult neurogenesis, can be outlined as the stepwise progression of NSCs into progenitor cells, neuroblast fate specification, neuronal differentiation in dentate granule cells (GCs), survival, and their synaptic integration into the existing circuitry to participate in the hippocampal function $[1,2]$.

Neural activity affects multiple stages of hippocampal adult neurogenesis, and it is well established that the $\gamma$-aminobutyric acid (GABA) neurotransmitter plays a major role in mediating activity-dependent regulation of the neuronal development process, considering the early expression of GABA receptors (GABARs) by NSCs [3]. Indeed, GABA, probably released by dentate parvalbumin-expressing interneurons, regulates NSC quiescence [4], neuronal fate specification [5], and synaptic neuron integration in the hippocampal circuit [6]. Its functions are first mediated by tonic activation of extrasynaptic ionotropic $\mathrm{GABA}_{\mathrm{A}}$ receptors onto newborn cells, and by phasic GABA activity when differentiating neurons receive GABAergic synaptic inputs from inhibitory interneurons of the subgranular zone and hilus [7].

Tonic and phasic GABA activity on maturating neurons generate membrane depolarizations due to an increased intracellular chloride concentration produced by high and low expression of 
$\mathrm{Na}^{+}-\mathrm{K}^{+}-\mathrm{Cl}^{-}$co-transporters (NKCC1) and $\mathrm{K}^{+}-\mathrm{Cl}^{-}$co-transporters (KCC2), respectively; as the neuronal maturation proceeds, a downregulation of NKCC1 and upregulation of KCC2 cotransporters occurs, thus dropping internal chloride concentration and making GABAergic signals hyperpolarizing [8]. The depolarizing activity of GABA onto adult-generated granule cells seems to be crucial for their maturation, probably due to calcium entry through low-voltage activated T-type $\mathrm{Ca}^{2+}$ channels (T-type VDCC) [6] precociously expressed by newborn cells.

In this context, we previously identified, in adult rat dentate gyrus, newborn granule cells at different stages of maturation, which exhibited peculiar morphological and electrophysiological properties [2] and synaptic input as well [9]. In line with literature evidence [10], our findings showed that at a very early stage of newborn neuron maturation, the stimulation of medial perforant pathway (MPP) or hilus did not evoke any detectable synaptic response, indicating the absence of functional synapses. At eight-day post-mitosis, developing neurons exhibited GABAergic synaptic input, eliciting small amplitude responses with slow kinetics, and T-type VDCC expression in the cell membrane (maturation stage reported as Class 2 subclass I in [2]). However, these very immature neurons also showed depolarized membrane potentials, likely inducing T-type VDCC inactivation, thus suggesting that GABA activity could not be able to promote increased calcium entry through T-type VDCC, as instead described for more mature newborn granule cells [10].

Additionally, we observed, during current-clamp recordings of newborn neurons at this very early maturation stage, the occurrence of resting membrane potential oscillations were not induced by synaptic activities, but likely spontaneously originated (unpublished data). Compelling evidence in literature points out that voltage-dependent calcium channels and calcium-activated potassium channels cooperate to generate robust membrane potential oscillations in several experimental models, thus regulating the intracellular calcium concentration [11-13].

Taking into account the above findings, we hypothesize that the spontaneous membrane potential oscillations recorded in 8-day old newborn granule cells (identified as Class 2 subclass I in [2]) may promote calcium entry and that $\mathrm{GABA}_{\mathrm{A}} \mathrm{R}$ opening contributes to intracellular calcium level regulation, decreasing input resistance and dampening membrane potential oscillations. To address this issue, in the present paper, patch-clamp and calcium imaging techniques are used to record very immature granule cells of adult rat dentate gyrus. Our findings highlight a novel molecular and electrophysiological mechanism through which GABA fine-tunes intracellular calcium homeostasis in rat adult-born granule neurons at a very early stage of maturation.

\section{Results}

\subsection{Functional Features of Immature Dentate Granule Cells with GABAergic Evoked Response}

Immature granule cells showing only the GABAergic evoked response were considered (previously classified as Class 2 subclass I, [2]: $\mathrm{RMP}=-51.8 \pm 0.9 \mathrm{mV}$; IR $=5888.6 \pm 299.1 \mathrm{M} \Omega ; \mathrm{C}=20.1 \pm 0.7 \mathrm{pF}$ ). Most of the recorded cells exhibited a GABAergic response to MPP stimulation with low amplitude and slow kinetic, and no spontaneous events (Figure 1A); only a few cells elicited a GABAergic response with faster kinetic and higher amplitude and a very low-frequency GABAergic spontaneous synaptic activity as well (Figure 1B). According to our previous works [2,9,14], MPP-evoked responses and spontaneous activities were fully and reversibly abolished by $10 \mu \mathrm{M} B M I$, indicating the implication of ionotropic $\mathrm{GABA}_{\mathrm{A}}$ receptors. The lack of any evoked glutamatergic currents was confirmed by recordings cells at $\mathrm{V}_{\text {-holding }}=-70 \mathrm{mV}$ and $+40 \mathrm{mV}$ at maximal stimulation. Gramicidin perforated patch-clamp $\left(n=4\right.$ cells) proved the depolarizing nature of $\mathrm{GABA}_{\mathrm{A}} \mathrm{R}$ currents elicited by $10 \mu \mathrm{M}$ muscimol local application (reversal potential measured $=-35.6 \pm 4.2$ ).

Depolarizing current injection in current-clamp mode, starting from a resting membrane potential of $-80 \mathrm{mV}$, induced three different kinds of voltage-sensitive non-linearities: (i) a potassium outward current; (ii) a high threshold TTX (500 nM) sensitive rudimentary spike; (iii) a low threshold verapamil $(20 \mu \mathrm{M})$ or $\mathrm{Ni}^{2+}(100 \mu \mathrm{M})$ sensitive slow spike. The low threshold activation and the sensibility 
to verapamil and nickel indicated that slow spikes were mediated by low-threshold T-type VDCC (Figure 1C). As expected, when the cells were depolarized starting from their resting membrane potential, it was not possible to elicit calcium spikes due to T-type VDCC inactivation (Figure 1D). In line with this, calcium spikes showed an activation threshold $(-64.5 \pm 2.1 \mathrm{mV})$ more hyperpolarized with respect to cell resting membrane potential $(-52.8 \pm 1.7 \mathrm{mV} ; n=8$ cells, paired T-test $p<0.001)$.

A
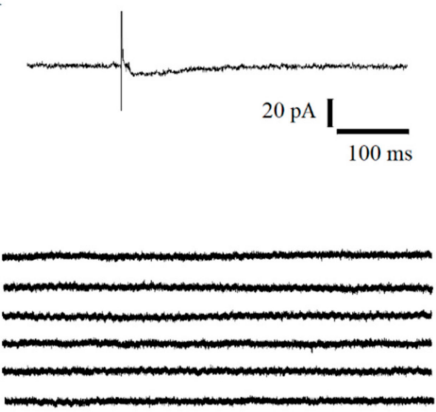

$20 \mathrm{pA} \quad$ I

$\overline{200 \mathrm{~ms}}$

C

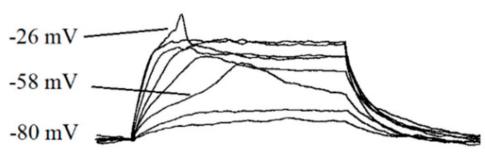

B
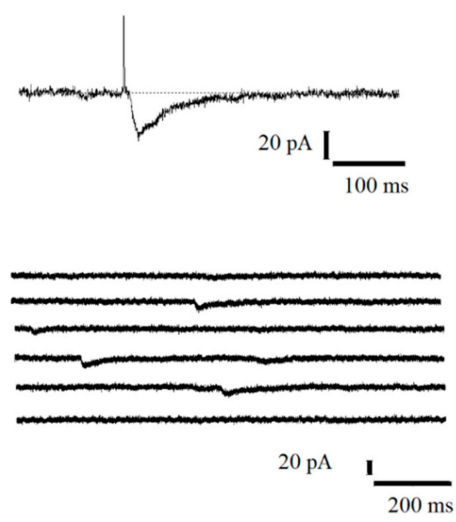

$\mathrm{D}$

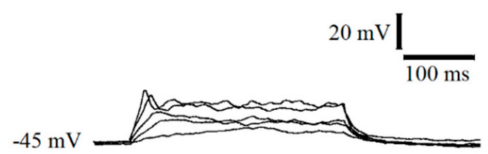

Figure 1. Functional features of immature dentate granule cells recorded in whole-cell configuration. $(\mathbf{A}, \mathbf{B})$ Voltage-clamp recordings (V-Holding $=-70 \mathrm{mV},\left[\mathrm{Cl}^{-}\right]_{\mathrm{i}}=34 \mathrm{mM}$ ) of the evoked response to MPP stimulation (top) and spontaneous activity (bottom) in two different immature neurons. (C,D) Current-clamp recordings of intrinsic excitability in response to depolarizing current steps in the same recorded cell. TTX-sensitive rudimentary spike (threshold about $-26 \mathrm{mV}$ ), and isolated and very slow $\mathrm{Ni}^{2+}$-sensitive spikes (threshold about $-58 \mathrm{mV}$ ) were elicited by depolarizing current steps starting from membrane potential of $-80 \mathrm{mV}$ (C). Depolarizing current steps starting from resting membrane potential $(-45 \mathrm{mV})$ were not able to elicit T-type VDCC spike due to their inactivation (D).

Glutamate receptor expression was investigated by glutamate $(100 \mu \mathrm{M})$ or N-Methyl-D-Aspartate (NMDA; $300 \mu \mathrm{M})$ application through micro-puffer apparatus and, consistent with our previous findings [15], an inward current was elicited when the cell was clamped at $-80 \mathrm{mV}$. At more depolarized holding potentials $(-20 \mathrm{mV})$, the inward current was followed by a robust outward current persisting after the end of glutamate application, which was blocked by TEA $(2 \mathrm{mM})$ or Paxilline $(10 \mu \mathrm{M})$ (Figure 2). The high paxilline sensibility and the voltage dependence indicated that the outward current was mediated by BK-type $\mathrm{Ca}^{2+}$-activated potassium channels.

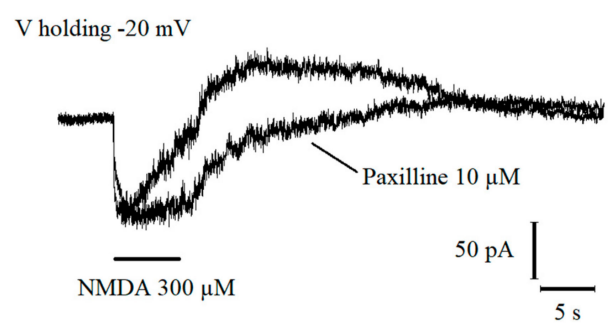

Figure 2. NMDA-induced BK channel activation via NMDARs in immature granule cells. Representative NMDA-induced current at $-20 \mathrm{mV}$ holding potential before and after paxilline $10 \mu \mathrm{M}$ bath application. 


\subsection{Resting Membrane Potential Oscillations and Intracellular $\mathrm{Ca}^{2+}$ Levels}

Cell body fluorescence changes (Figure 3A) were analyzed by switching the recording mode from current-clamp to voltage-clamp, setting the membrane potential at the value measured immediately after the establishment of whole-cell configuration. Low noise recordings were obtained in voltage-clamp mode, due to the poor or absent spontaneous synaptic activity. On the contrary, current-clamp mode was characterized by high noise recordings with robust hyperpolarizing and depolarizing membrane potential oscillations (Figure 3B). Interestingly, cell body fluorescence decreased significantly switching from current-clamp mode to voltage-clamp mode, and it fully recovered, switching back to current-clamp mode (Figure 3C,D).

$\mathbf{A}$

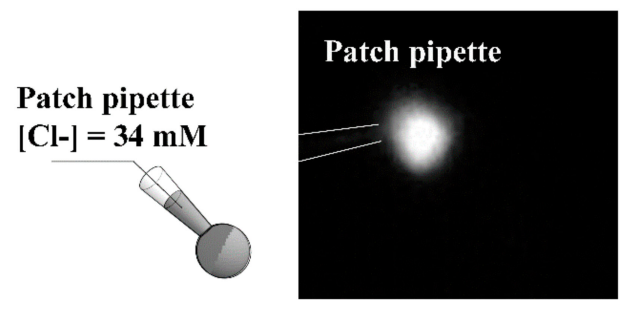

C

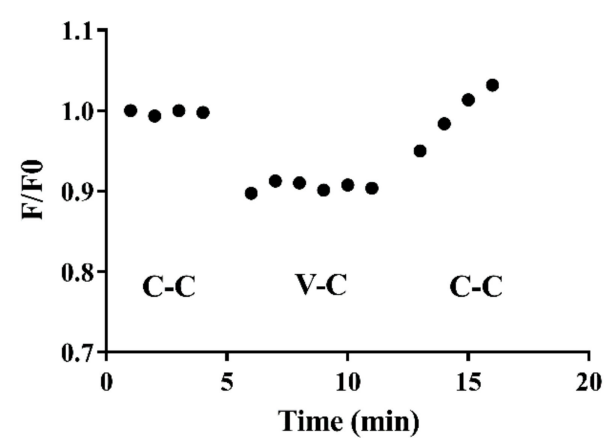

B

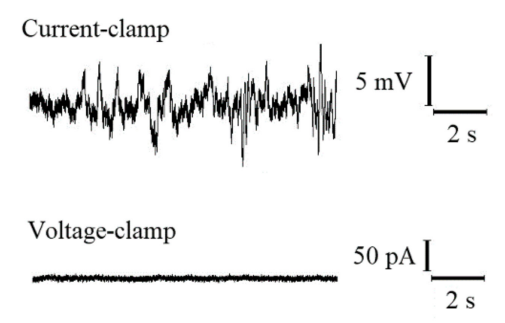

D

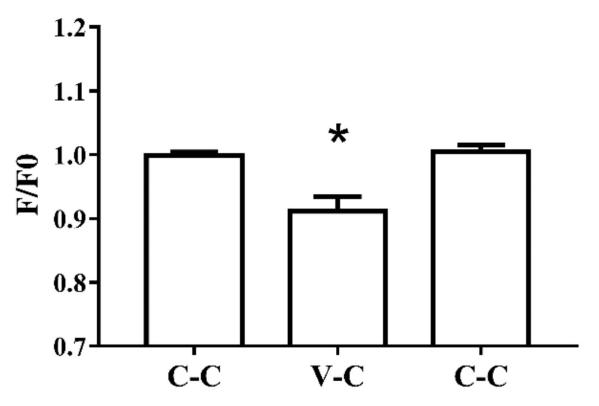

Figure 3. Membrane potential oscillations regulate the intracellular calcium levels. (A) Representation of single-cell $\mathrm{Ca}^{2+}$ imaging method and fluorescence image of a recorded immature neuron. The intracellular solution contained $34 \mathrm{mM} \mathrm{Cl}^{-}$and $100 \mu \mathrm{M}$ Fluo4. (B) Resting membrane potential oscillations recorded in current-clamp mode (top trace) and low-noise voltage-clamp recording at the same potential in the same cell (bottom trace). (C) Representative course of cell body fluorescence in a recorded immature neuron obtained by switching recording mode from current-clamp (C-C) to voltage-clamp (V-C) and vice versa. (D) Significative decrease of $\left[\mathrm{Ca}^{2+}\right]_{\mathrm{I}}$ obtained by switching from current-clamp mode to voltage-clamp mode; the reduction reversed by switching back to current-clamp mode (RM one-way ANOVA F $(2,5)=15.28 p<0.01$, Tukey's posthoc test ${ }^{*}$ ) V-C vs. both C-C, $p<$ $0.05)$.

\subsection{Membrane Channels Involved in Resting Membrane Potential Oscillations}

Resting membrane potential oscillations were investigated by perfusion bath application of specific channel/receptor agonists and blockers.

To evaluate if membrane potential oscillations could be linked to intracellular $\mathrm{Ca}^{2+}$ level changes, $200 \mu \mathrm{M} \mathrm{Ni}^{2+}$, a T-type VDCC blocker, was applied during immature granule cell recordings. A significant decrease in both membrane noise and intracellular $\mathrm{Ca}^{2+}$ concentration was found, without any alteration of the resting membrane potential mean value (Figure 4A, Table 1). 
A

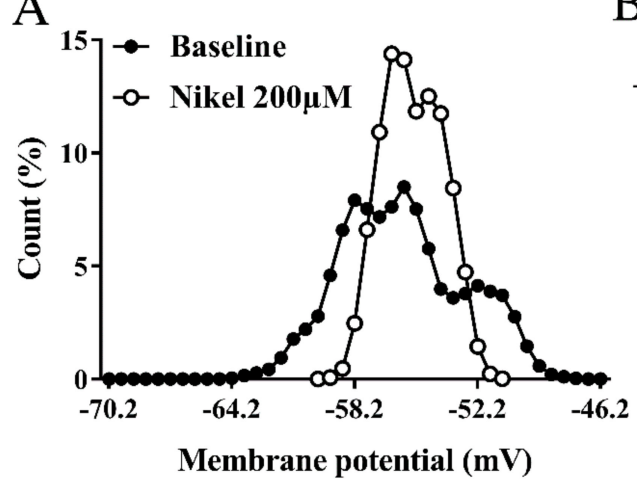

B

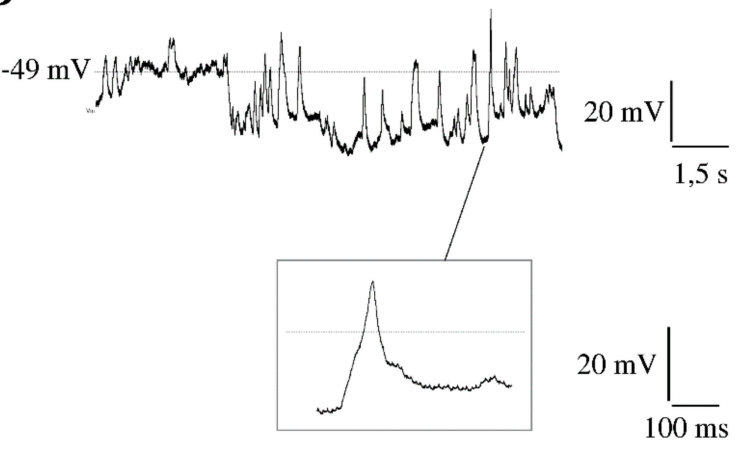

Figure 4. Membrane potential oscillations in immature granule cells. (A) Representative graph of membrane potential noise distribution recorded in immature neurons before and after $200 \mu \mathrm{M}$ nickel application to the bath perfusion. (B) Robust spontaneous hyperpolarizing events recorded in current-clamp mode in immature neuron, showing a mean resting membrane potential of $-49 \mathrm{mV}$.

A T-type VDCC spike-like event is enlarged in the box.

Considering that NMDARs and calcium-permeable AMPARs could represent an additional source of calcium, NMDAR and AMPAR blockers were applied to disclose a possible involvement of glutamate ambient in membrane noise induction. The addition of both $50 \mu \mathrm{M}$ AP5 (an NMDAR blocker) and 10 $\mu \mathrm{M}$ CNQX (an AMPAR blocker) to the recording solution did not affect resting membrane potential noise and intracellular calcium level as well (Table 1).

During recordings, immature neurons showed robust hyperpolarizing bursts that, due to their amplitude, were assumed to be mediated by the BK channel opening (Figure 4B). Thus, a specific blocker of the BK channel, Paxilline $(10 \mu \mathrm{M})$, was added to the perfusion bath. Both membrane potential oscillations and intracellular calcium levels significantly decreased (Table 1).

Then, to test the possible implication of $\mathrm{GABA}_{\mathrm{A}} \mathrm{R}$ activation in intracellular calcium level variations and in membrane noise, GABA $(10 \mu \mathrm{M})$ or muscimol $(10 \mu \mathrm{M})$ were applied to the bath solution during immature cell recordings. In both experimental conditions, a significant reduction in intracellular calcium concentration and membrane potential noise was found (Table 1). During agonist application, RMP was close to the chloride equilibrium potential, thus inducing a slight membrane depolarization, which was not able to increase intracellular calcium level, probably due to T-Type VDCC inactivation. However, $\mathrm{GABA}_{\mathrm{A}} \mathrm{R}$ opening decreased IR (data not shown), thus shunting membrane currents and dampening resting membrane potential oscillations. 
Table 1. Effects of channel/receptor agonist and blocker application on FWHM, F/F0, and RMP in the recorded immature neurons.

\begin{tabular}{|c|c|c|c|c|c|c|c|c|c|c|c|c|c|c|c|}
\hline \multirow{4}{*}{ Treatment } & \multicolumn{15}{|c|}{ FWHM (mv) } \\
\hline & \multicolumn{7}{|c|}{ Descriptive Statistics } & \multicolumn{2}{|c|}{ RM-One-Way Anova } & \multicolumn{6}{|c|}{ Tukey HSD } \\
\hline & \multirow{2}{*}{$n$} & \multicolumn{2}{|c|}{ BL } & \multicolumn{2}{|c|}{ TREAT } & \multicolumn{2}{|c|}{ REV } & \multirow{2}{*}{$F(d f)$} & \multirow{2}{*}{$p$} & \multicolumn{2}{|c|}{ BL $v s$. TREAT } & \multicolumn{2}{|c|}{ BL $v s$. REV } & \multicolumn{2}{|c|}{ TREAT $v s$. REV } \\
\hline & & Mean & SEM & Mean & SEM & Mean & SEM & & & Mean Diff. & $p$ & Mean Diff. & $p$ & Mean Diff. & $p$ \\
\hline $\begin{array}{c}\text { Nikel } \\
200 \mu \mathrm{M}\end{array}$ & 7 & 3.8 & 0.5 & 2.4 & 0.4 & 3.6 & 0.5 & $F(2,6)=10.98$ & 0.005 & 1.71 & 0.03 & 0.20 & $n s$ & -1.51 & 0.02 \\
\hline $\begin{array}{c}\mathrm{AP5} \\
50 \mu \mathrm{M} \\
\end{array}$ & 6 & 4.9 & 0.7 & 4.8 & 0.7 & 4.2 & 0.6 & $\mathrm{~F}(2,5)=0.79$ & ns & 0.11 & $n s$ & 0.66 & $n s$ & 0.55 & ns \\
\hline $\begin{array}{l}\text { CNQX } \\
10 \mu \mathrm{M}\end{array}$ & 5 & 4.8 & 0.9 & 4.7 & 0.9 & 4.2 & 0.8 & $\mathrm{~F}(2,4)=0.56$ & ns & 0.08 & ns & 0.64 & $n s$ & 0.56 & ns \\
\hline $\begin{array}{c}\text { Paxilline } \\
10 \mu \mathrm{M}\end{array}$ & 8 & 2.5 & 0.1 & 1.8 & 0.1 & 2.7 & 0.2 & $\mathrm{~F}(2,7)=12.71$ & 0.004 & 0.77 & 0.001 & -0.12 & $n s$ & -0.9 & 0.01 \\
\hline $\begin{array}{l}\text { GABA } \\
10 \mu \mathrm{M}\end{array}$ & 10 & 5.2 & 0.5 & 3.5 & 0.3 & 4.6 & 0.5 & $\mathrm{~F}(2,9)=4.01$ & 0.049 & 1.68 & 0.02 & 0.54 & $n s$ & -1.14 & ns \\
\hline Muscimol $10 \mu \mathrm{M}$ & 8 & 5.6 & 0.6 & 3.2 & 0.3 & 5.6 & 1.0 & $\mathrm{~F}(2,7)=4.97$ & 0.04 & 2.36 & 0.007 & -0.03 & $n s$ & -2.4 & $n s$ \\
\hline \multicolumn{16}{|c|}{ F/F0 } \\
\hline $\begin{array}{c}\text { Nikel } \\
200 \mu \mathrm{M}\end{array}$ & 10 & 1.01 & 0.01 & 0.91 & 0.02 & 0.94 & 0.03 & $F(2,9)=9.63$ & 0.002 & 0.09 & 0.004 & 0.06 & $n s$ & -0.03 & ns \\
\hline $\begin{array}{c}\text { AP5 } \\
50 \mu \mathrm{M} \\
\end{array}$ & 7 & 1.01 & 0.01 & 1.01 & 0.02 & 1.03 & 0.03 & $\mathrm{~F}(2,6)=0.17$ & $n s$ & 0.00 & $n s$ & -0.01 & $n s$ & -0.01 & $n s$ \\
\hline $\begin{array}{l}\text { CNQX } \\
10 \mu \mathrm{M}\end{array}$ & 5 & 1.00 & 0.01 & 1.02 & 0.02 & 1.07 & 0.05 & $F(2,4)=0.83$ & ns & -0.02 & ns & -0.06 & $n s$ & -0.04 & ns \\
\hline $\begin{array}{c}\text { Paxilline } \\
10 \mu \mathrm{M}\end{array}$ & 8 & 1.02 & 0.01 & 0.77 & 0.05 & 0.7 & 0.07 & $F(2,7)=17.02$ & 0.001 & 0.24 & 0.008 & 0.31 & .007 & 0.07 & $n s$ \\
\hline $\begin{array}{l}\text { GABA } \\
10 \mu \mathrm{M} \\
\end{array}$ & 6 & 0.99 & 0.00 & 0.92 & 0.02 & 1.00 & 0.00 & $F(2,5)=15.86$ & 0.009 & 0.07 & 0.02 & -0.01 & $n s$ & -0.07 & .02 \\
\hline Muscimol $10 \mu \mathrm{M}$ & 9 & 1.00 & 0.01 & 0.88 & 0.03 & 0.93 & 0.06 & $\mathrm{~F}(2,8)=4.42$ & 0.04 & 0.14 & 0.01 & 0.06 & $n s$ & -0.07 & ns \\
\hline \multicolumn{16}{|c|}{ RMP (mv) } \\
\hline $\begin{array}{c}\text { Nikel } \\
200 \mu \mathrm{M}\end{array}$ & 8 & -55.8 & 4.9 & -55.4 & 5.3 & -55.8 & 5.3 & $F(2,7)=0.03$ & ns & -0.31 & $n s$ & 0.06 & $n s$ & 0.37 & $n s$ \\
\hline $\begin{array}{c}\mathrm{AP5} \\
50 \mu \mathrm{M} \\
\end{array}$ & 6 & -52.3 & 2.6 & -52.0 & 2.5 & -55.2 & 3.2 & $F(2,5)=2.31$ & ns & -0.33 & $n s$ & 2.83 & $n s$ & 3.16 & ns \\
\hline $\begin{array}{l}\text { CNQX } \\
10 \mu \mathrm{M} \\
\end{array}$ & 5 & -52.8 & 2.0 & -52.6 & 2.2 & -51.8 & 2.1 & $\mathrm{~F}(2,4)=2.31$ & $n s$ & -0.20 & $n s$ & -1.00 & $n s$ & -0.8 & $n s$ \\
\hline $\begin{array}{c}\text { Paxilline } \\
10 \mu \mathrm{M}\end{array}$ & 6 & -49.7 & 2.1 & -41.8 & 4.8 & -42.8 & 5.7 & $\mathrm{~F}(2,5)=4.20$ & ns & -7.83 & ns & -6.83 & $n s$ & 1.00 & $n s$ \\
\hline $\begin{array}{l}\text { GABA } \\
10 \mu \mathrm{M}\end{array}$ & 8 & -49.3 & 2.2 & -41.1 & 1.4 & -53.3 & 1.8 & $F(2,7)=19.56$ & 0.0004 & -8.12 & 0.02 & 4.00 & $n s$ & 12.13 & 0.0001 \\
\hline Muscimol $10 \mu \mathrm{M}$ & 8 & -50.1 & 2.5 & -41.0 & 1.3 & -52.5 & 1.7 & $\mathrm{~F}(2,7)=14.77$ & 0.001 & -9.12 & 0.015 & 2.37 & $n s$ & 11.5 & 0.0003 \\
\hline
\end{tabular}




\subsection{Hippocampal Circuit Activity and Intracellular Calcium Level in Immature Neurons}

The effect of the physiologically released GABA neurotransmitter on very immature neurons was evaluated by stimulating MPP. To obtain a constant extracellular GABA concentration, low-frequency stimulation was applied to MPP ( $3 \mathrm{~min}, 2.5 \mathrm{~Hz}$ ). GABAergic responses could be evoked by immature synapse activation onto newborn neurons or by GABA spillover from mature synapses close to the recorded neuron.

MPP stimulation induced a slight depolarization (thus moving resting membrane potential towards the chloride equilibrium potential), and decreased intracellular calcium level as well (Figure 5A-C). This result was consistent with those obtained by applying GABA or muscimol to the perfusion bath. The noise analysis was not performed due to the recording contamination by stimulus artifact, but a reduction of membrane potential oscillations during stimulation could be appreciated (Figure 5A).
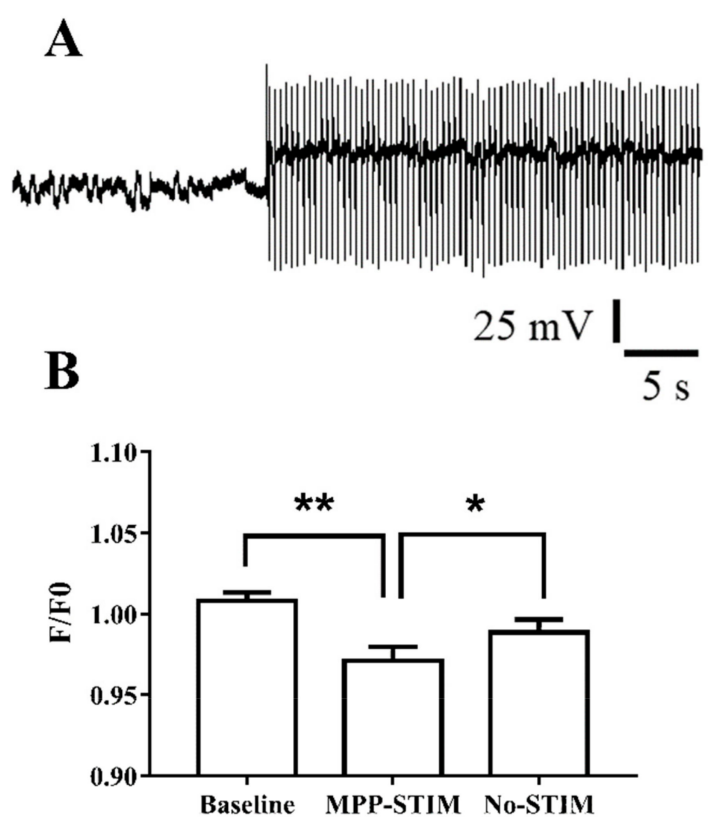

C

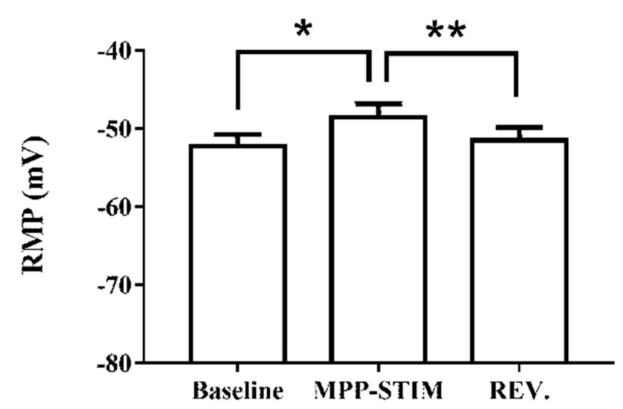

Figure 5. $\mathrm{GABA}_{\mathrm{A}} \mathrm{R}$ activation by MPP stimulation regulates intracellular calcium concentration. (A) Typical response evoked by MPP stimulation $(2.5 \mathrm{~Hz}$ ) recorded in current-clamp mode. MPP stimulation induced a constant slight depolarization shifting membrane potential close to the $\mathrm{Cl}^{-}$equilibrium. Even if the trace is disturbed by artifacts, it is possible to note the reduction of potential oscillations during stimulation. (B) Prolonged MPP stimulation ( $3 \mathrm{~min}$ ) induced a significant and reversible decrease of $\left[\mathrm{Ca}^{2+}\right]_{\mathrm{I}}$ and membrane depolarization, as well $(\mathbf{C}) . \mathrm{F} / \mathrm{F} 0, \operatorname{RM}$ one-way $\operatorname{ANOVA~F}(2,12)=11.38 p<0.01$, Tukey's post hoc test $(* *)$ baseline vs. MPP-STIM $p<0.01,\left({ }^{*}\right)$ MPP-STIM vs. No-STIM $p<0.05$. RMP, RM one-way ANOVA F $(2,12)=9.374 p<0.01$, Tukey's post hoc test $\left(^{*}\right)$ baseline vs. MPP-STIM $p<$ $\left.0.05,{ }^{* *}\right)$ MPP-STIM vs. No-STIM $p<0.01$. 


\subsection{Interaction between BK Channels and T-Type Voltage-Dependent $\mathrm{Ca}^{2+}$ Channels}

As mentioned above, all recorded cells showed a robust membrane noise in current-clamp mode, and, in some of them, it was also possible to distinguish a hyperpolarizing burst showing the typical shape of the RC circuit response to square hyperpolarizing current (Figure 6A). Furthermore, at the end of the hyperpolarizations, a depolarizing event similar to the T-type calcium spike (Figure 6A) was frequently detectable. In principle, this is consistent with the fact that in immature neurons, showing depolarized resting membrane potential, the only way to open T-Type calcium channels relies on hyperpolarizing events able to remove ion channel inactivation. Therefore, to verify this possibility, spontaneous hyperpolarization was simulated using increasing hyperpolarizing current steps (300-600 ms) in current-clamp mode, and a $\mathrm{Ni}^{2+}$-sensitive calcium spike was elicited in all recorded immature neurons (Figure 6B).

A

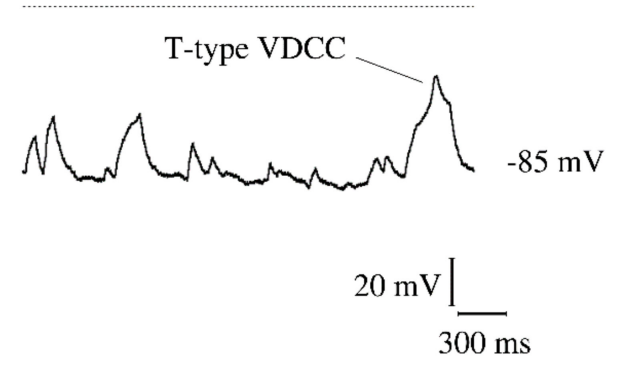

B

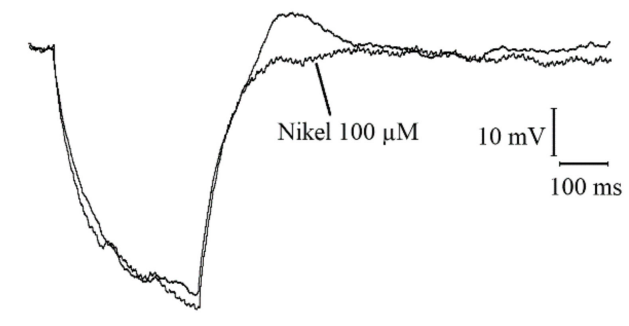

C

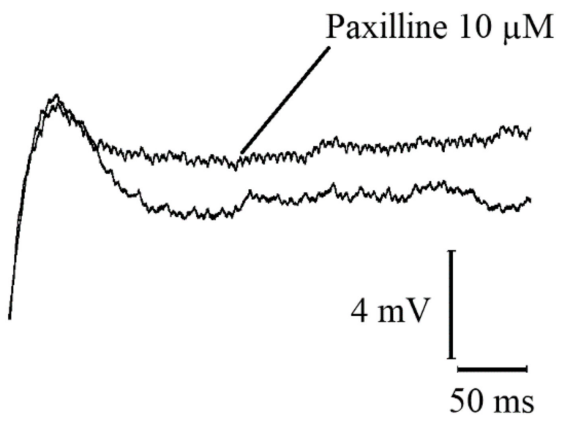

D

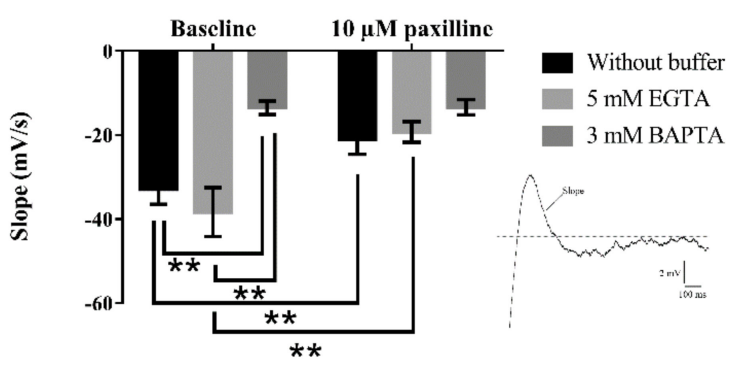

Figure 6. BK channels and T-type VDCC interaction. (A) Hyperpolarizing spontaneous burst recorded in current-clamp mode in immature neuron with resting membrane potential mean value of $-52 \mathrm{mV}$. (B) $\mathrm{Ni}^{2+}$-sensitive T-type VDCC spikes induced by hyperpolarizing current steps starting from resting membrane potential. (C) Paxilline-sensitive after-hyperpolarization induced by T-type VDCC spike. (D) BK-mediated after-hyperpolarization, quantified as the slope of calcium spike repolarization (inset in the graph), recorded using different intracellular calcium chelators. Two-way RM ANOVA with Paxilline treatment and Intracellular buffer as independent variables; Paxilline treatment $\mathrm{F}(1,18)=26.82$ $p<0.01$, Intracellular buffer $\mathrm{F}(2,18)=9.256 p<0.01$. Tukey's multiple comparisons test $(* *)$ baseline vs. $10 \mu \mathrm{M}$ paxilline without buffer $p<0.01,\left({ }^{* *}\right)$ baseline vs. $10 \mu \mathrm{M}$ paxilline $5 \mathrm{mM}$ EGTA $\left.p<0.01,{ }^{* *}\right)$ baseline without buffer vs. baseline 3 mM BAPTA $p<0.01,\left({ }^{* *}\right)$ baseline 5 mM EGTA vs. baseline $3 \mathrm{mM}$ BAPTA $p<0.01$.

Interestingly, calcium spike was followed by a hyperpolarization (after-hyperpolarization), which suggested a possible involvement of calcium-activated potassium channels. To test this hypothesis, $10 \mu \mathrm{M}$ paxilline, a specific BK channel blocker, was applied to the recording bath. Paxilline fully abolished the after-hyperpolarization, thus confirming the involvement of this type of potassium channels (Figure 6C).

BK channel requires high intracellular $\mathrm{Ca}^{2+}$ concentration for opening, and this may occur when the channel is closely apposed to the calcium channels forming a heteromeric complex [16]. To verify 
this possibility, different intracellular calcium chelators were used during current-clamp recordings. T-Type-mediated calcium spikes were able to elicit paxilline-sensitive hyperpolarization in absence of intracellular calcium buffers or in presence of $5 \mathrm{mM}$ EGTA (Figure 6D). In sharp contrast, fast calcium buffer BAPTA ( $3 \mathrm{mM})$ added to the intracellular solution, completely abolished calcium-induced hyperpolarization sensitive to paxilline (Figure 6D), thus suggesting a physical and functional coupling between BK channels and T-Type VDCCs.

Finally, the analysis of membrane noise revealed that membrane potential oscillations were attenuated by increasing intracellular calcium buffer capacity (Figure 7).

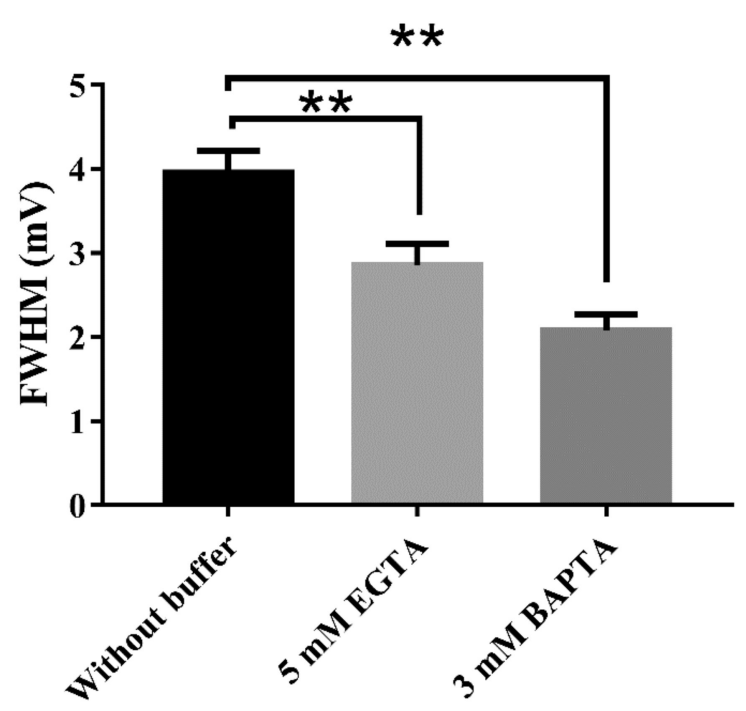

Figure 7. Resting membrane potential oscillations and intracellular calcium concentration. Membrane potential oscillations decreased by increasing calcium buffer capacity. One-way ANOVA F $(2,17)=$ $16.28 p<0.01$, Tukey's multiple comparisons test $\left({ }^{* *}\right)$ without buffer vs. 5 mM EGTA $p<0.01,\left({ }^{* *}\right)$ without buffer vs. $3 \mathrm{mM}$ BAPTA $p<0.01$.

\section{Discussion}

In the present work, spontaneous membrane potential oscillations observed in very immature neurons of adult rat dentate gyrus were related to intracellular calcium level alterations and their modulation by GABA activity was investigated. The main results we found were the following: (i) resting membrane potential oscillations were able to elicite calcium entry into the cell, thus increasing intracellular calcium concentration; (ii) BK channels and T-Type VDCCs were involved in generating membrane potential oscillations; (iii) $\mathrm{GABA}_{\mathrm{A}} \mathrm{R}$ activation was able to decrease intracellular calcium level, probably shunting membrane currents and dampening resting membrane potential oscillations. Altogether, these findings outline a novel mechanism through which GABA regulates intracellular calcium homeostasis in rat adult-born granule neurons at a very early stage of their maturation (Figure 8). 


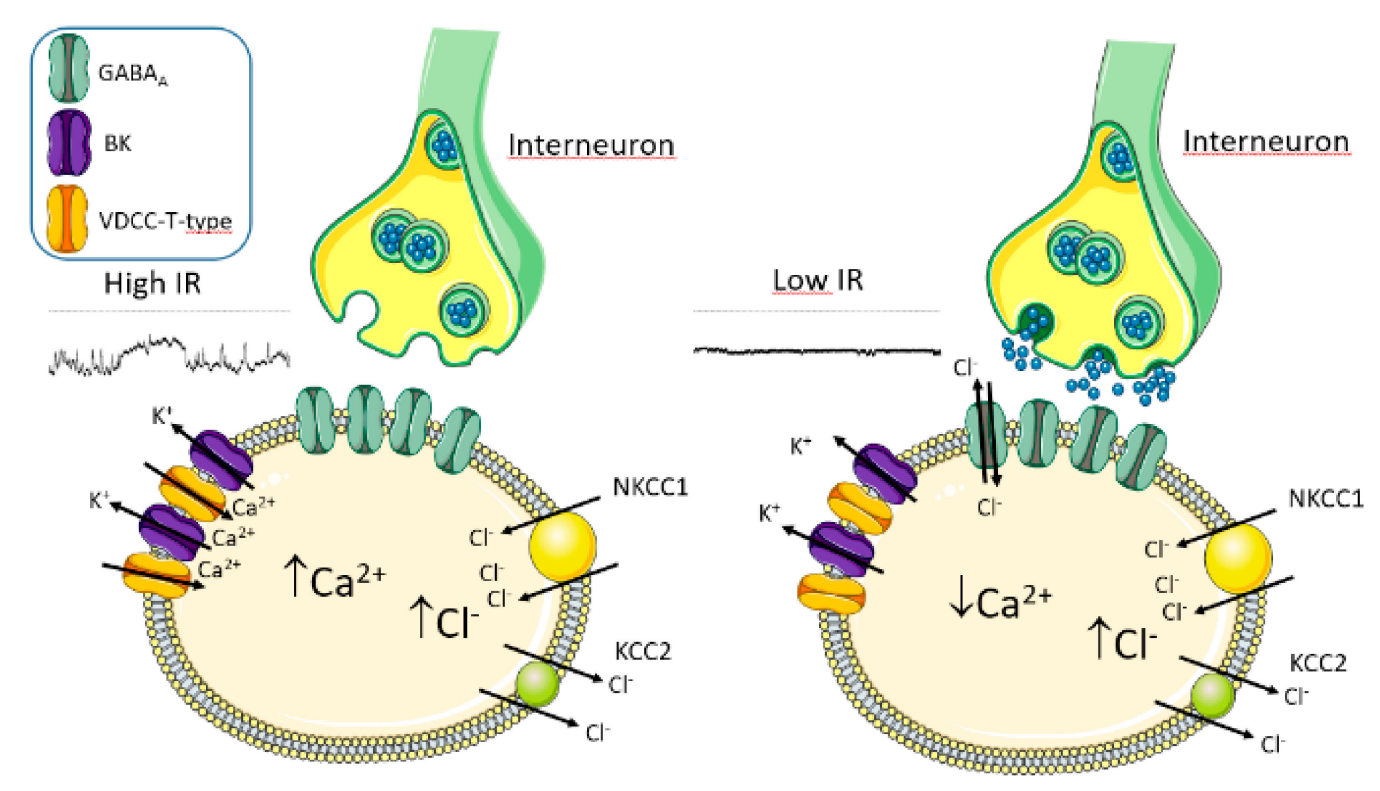

A

B

Figure 8. Schematic illustration showing the implication of BK channels, T-type VDCC, and $G_{A B A_{A}} R$ in intracellular calcium level regulation. (A) When the extracellular GABA concentration is low, GABA $\mathrm{Rs}_{\mathrm{A}}$ are closed, immature neurons have a very high IR, and generate membrane potential oscillations through BK and T-type calcium channel activity. Specifically, robust BK-induced hyperpolarizations elicit T-type VDCC voltage sensor activation and gate opening, which increases calcium entry. In turn, calcium influx quickly activates BK channels, due to their physical interaction (according to the literature [17]), inducing hyperpolarizations. This mechanism is facilitated by low calcium buffer levels present in

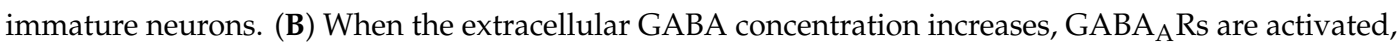
inducing membrane current shunt. BK-induced hyperpolarization is damped, preventing T-type VDCC opening. Therefore, an increased hippocampal activity through $\mathrm{GABA}_{\mathrm{A}} \mathrm{R}$ action can promote a lowering of intracellular calcium level. This figure was prepared using the Neuroscience-PPT-Toolkit-Suite of Motifolio Inc., USA, and Servier Medical Art (https://smart.servier.com/).

Our findings seem not to be consistent with the well-documented hypothesis that GABAergic activity induces intracellular calcium elevation in immature neurons $[5,18,19]$. Such discrepancy may conceivably be explained, taking into account that in our experimental model, the recorded developing granule neurons show a resting membrane potential, definitely more depolarized compared to T-type VDCC threshold activation, thus inducing calcium channel inactivation. Therefore, although GABA is depolarizing, moving resting membrane potential towards the chloride equilibrium potential, there are not the electrical conditions needed for T-type VDCC opening and the resulting calcium influx. Of course, we cannot rule out the possibility that GABAergic depolarizing activity may activate T-type VDCCs when it occurs in conjunction with a hyperpolarizing spontaneous event or in less immature neurons showing a resting membrane potential more hyperpolarized compared to T-type VDCC threshold, as we previously demonstrated (Class 2 subclass III described in [2]).

Concerns on technical caveats in patch-clamp recordings of resting membrane potentials may arise considering, in particular, the high IR of immature neurons that might introduce an error leading to underestimating RMP values. However, this error can be avoided by performing a high resistance seal onto the cell membrane (approximately 10-times higher than cell IR), as described in the literature [20-22]. Therefore, we believe our results are reliable because of the high resistance seals we obtained onto the membrane of the recorded immature neurons, as recommended in the literature. In addition, the maturation stage of newborn neurons we analyzed in this work was earlier than that 
of immature neurons considered in the investigations performed by other authors [10,20-22], as can be inferred comparing their functional features.

The passive membrane properties and the depolarized resting membrane potential of the examined immature neurons induce the activation of a mechanism that generates membrane potential oscillations and calcium influx by involving BK channels. The BK channel is characterized by an exceptionally large single-channel conductance, and it can be synergistically activated by membrane depolarization and elevation of intracellular $\mathrm{Ca}^{2+}$ concentration, resulting in membrane repolarization and voltage-dependent $\mathrm{Ca}^{2+}$ channel closing to reduce $\mathrm{Ca}^{2+}$ entering the cell. However, the BK opening probability may be increased by the presence in the channel structure of $\beta 4$ subunits, being able to shift the voltage dependence to more negative potentials $[23,24]$, and by the proximity of a calcium source. The expression of BK- $\beta 4$ subunits in the plasma membrane of dentate granule cells was demonstrated by Brenner and colleagues [25]. This result, together with our present findings, indicating a clustering between the BK channel and T-type VDCC, allow us to assert that the conditions to increase the BK channel opening probability exist in the immature neurons. In addition, the low intracellular calcium buffer, described in newborn dentate granule cells by Stocca and colleagues [26], represents a further favorable condition for BK opening.

It is known that BK channels in mature dentate granule cells form complexes with NMDA receptors [27], and this structural and functional coupling might also occur in immature neurons. In line with this, we found a robust BK current after local NMDA or glutamate application onto the recorded immature neurons, but ambient glutamate levels were not able to open NMDARs in our experimental conditions. Nevertheless, we cannot rule out a role of these receptors on membrane potential oscillations and intracellular calcium regulation in the intact brain.

Concerning the meaning of the electrophysiological and molecular mechanism we highlighted, it has to be taken into account that the features of the immature neurons examined in this work indicate their low probability of sending information in the hippocampal circuit, especially because of a very high threshold and low amplitude of action potential (see Figure 1 and [2]). Therefore, the new granule neurons at this early stage of maturation, even though contacted, may not play a significant role in the hippocampal function. Thus, phasic and tonic GABA activity related to hippocampal activation might affect immature neuron developmental process, such as dendritic arborization, neuronal migration [28-30], as well as cell survival, likely by influencing intracellular calcium fluctuations.

Along this line of reasoning, we previously demonstrated in the adult rat dentate gyrus that hippocampal circuitry activation, related to physical activity and behavioral experiences, promotes anticipation of GABA synaptogenesis and T-type VDCC appearance onto 1-week-old newborn neurons $[9,14]$ and that the survival of newborn cells was enhanced [31]. Therefore, considering the present findings, we may speculate that GABA input activation, related to hippocampal function, prevents newborn cell death by modulating intracellular $\mathrm{Ca}^{2+}$ transients. Indeed, based on the mechanism here described, $\mathrm{GABA}_{\mathrm{A}} \mathrm{R}$ activation stabilizes the membrane potential at the $\mathrm{Cl}^{-}$equilibrium potential, that in immature neurons is depolarized compared to the RMP, thus quenching the membrane potential oscillations generated by the coordinated activity of BK channel and T-type VDCC complexes during which calcium influx occurs.

In conclusion, our findings provide a significant contribution to understanding how adult-generated new neurons in the early stage of their maturation can regulate intracellular calcium levels, and highlight an unconventional role of GABA activity in intracellular calcium homeostasis. The electrophysiological and molecular mechanism here defined could also occur in immature neurons generated during brain development, which show functional features very similar to those of maturating neurons we have considered in this work and that have been described by Pedroni and colleagues in developing dentate gyrus [32].

Finally, future experiments will be required to verify the implication of the described mechanism in promoting newborn neurons survival. 


\section{Materials and Methods}

\subsection{Animals and Slices Preparation}

We used Sprague-Dawley male rats (6-8-week-old, $n=25)$ in accordance with the Italian law on animal experimentation (D.lgs. 26/2014; research project permitted with authorization N. 465/2015-PR by Italian Ministry of Health). Animals were housed two per cage, where access to food and water was free. Room temperature was kept at $21 \pm 1{ }^{\circ} \mathrm{C}$, humidity was $50 \%+5 \%$, and light/dark cycle was 12-12 h (light on at 7.00 a.m.). Rats did not undergone any procedure, but were anesthetized with ketamine $(65 \mathrm{mg} / \mathrm{kg}$ b.w.) and killed by decapitation. Brain was rapidly removed, and $400 \mu \mathrm{m}$-thick hippocampal transversal slices were prepared, as previously described [33]. Slices were recovered in oxygenated artificial cerebrospinal fluid (ACSF, containing in mM: $125 \mathrm{NaCl}, 2.5 \mathrm{KCl}, 1.3 \mathrm{NaH}_{2} \mathrm{PO}_{4}$, $25 \mathrm{NaHCO}_{3}, 2 \mathrm{CaCl}_{2}, 1.3 \mathrm{MgCl}_{2}, 1.3 \mathrm{Na}^{+}$ascorbate, $0.6 \mathrm{Na}^{+}$pyruvate, 10 dextrose; $\mathrm{pH}=7.4 ; 320$ $\mathrm{mOsm}$ ) for at least $1 \mathrm{~h}$ at room temperature, and then were transferred to the recording chamber where slices were continuously perfused $(2 \mathrm{~mL} / \mathrm{min})$ with the saline solution. Patch-clamp recordings, in whole-cell or perforated configuration, were carried out under visual guidance using a Zeiss Axioskop microscope (Carl Zeiss International, Milan, Italy) equipped with an infrared light-sensitive camera connected to a monitor.

\subsection{Patch-Clamp Recordings}

Whole-cell recordings were performed by using patch pipettes filled with an internal solution that mimicked the intracellular environment of immature neurons (high intracellular chloride concentration assessed by perforated patch recordings). This solution contained in mM: 100 potassium gluconate, 26 $\mathrm{KCl}, 8 \mathrm{NaCl}$, 0.2 EGTA, 10 HEPES, $3 \mathrm{Mg}_{2} \mathrm{ATP}, 0.3 \mathrm{GTP}$ ( $\mathrm{pH}=7.2 ; 290 \mathrm{mOsm}$ ). In some experiments, intracellular calcium buffer concentration was increased by using 5 mM EGTA or 3 mM BAPTA. To minimize errors on membrane potential measure, we performed high resistance seals on the cell membrane (above $100 \mathrm{G} \Omega$ ). Immature granule cells belonging to Class 2 subclass I, according to our previously reported classification [2], were electrophysiologically identified to be included in the present work. Cell access was obtained in the voltage-clamp mode, and resting membrane potential (RMP) was evaluated immediately upon break-in. Membrane potentials were measured with correction for liquid junction potentials. Passive membrane properties, such as input resistance (IR) and capacitance (C), were calculated in response to a $300 \mathrm{~ms}, 5 \mathrm{mV}$ hyperpolarizing pulse. To evaluate cell excitability, we measured membrane potential in response to depolarizing and hyperpolarizing current pulses (5 pA steps). T-Type VDCC opening was obtained in current-clamp mode, using two different ways: (i) by depolarizing current pulses (300 ms) starting from a holding potential of about $-80 \mathrm{mV}$; and (ii) by hyperpolarizing pulses (300-600 ms) starting from resting membrane potential (about $-50 \mathrm{mV}$ ). Synaptically evoked responses were elicited using a bipolar stimulating electrode pulled from theta capillary (World Precision Instruments) and filled with ACSF solution. The bipolar electrode was placed in the molecular layer to activate the medial perforant pathway. Postsynaptic currents (PSCs) were evoked with an interstimulus frequency of $0.033 \mathrm{~Hz}$ for synaptic characterization or with $2.5 \mathrm{~Hz}$ (3 $\mathrm{min}$ ) stimulation to obtain prolonged and constant GABA release from hilar interneurons.

Patch-clamp recordings in a perforated configuration were carried out as previously described [10] by using an internal solution containing in mM: $134 \mathrm{KCl}, 0.2$ EGTA, $10 \mathrm{HEPES}$, and $5 \mu \mathrm{g} / \mathrm{mL}$ gramicidin.

\subsection{Calcium Imaging}

Calcium imaging recordings were performed in whole-cell configuration using Fluo-4 pentapotassium salt, a calcium indicator dye (Thermo Fisher, Waltham, MA, USA), as previously described [34]. Briefly, the experiments were carried out using a Zeiss Axioskop microscope (Carl Zeiss International, Italy) equipped with a $40 \times$ water immersion objective and the Orca Flash 4.0 CCD camera (C11440, Hamamatsu, Japan), an Axopatch-200B amplifier (Axon Instruments, San Jose, CA, USA) and WinFluor software (Strathclyde Imaging Software V 3.8.7, John Dempster, University of 
Strathclyde, UK). Patch pipettes were filled with an intracellular solution containing in millimolar: 100 potassium gluconate, $26 \mathrm{KCl}, 8 \mathrm{NaCl}$, 0.2 EGTA, 10 HEPES, $3 \mathrm{Mg}_{2}$ ATP, $0.3 \mathrm{GTP}, 100 \mu \mathrm{M}$ Fluo4 $(\mathrm{pH}=7.2 ; 290 \mathrm{mOsm})$. Fluorescence images $(100 \times 100$ pixels $)$ were acquired at $100 \mathrm{~Hz}$ frequency using a FITC excitation filter of $450-490 \mathrm{~nm}$ and fluorescence values were expressed as F/F0 where $\mathrm{F} 0$ is the fluorescence at the start of recording. Fluorescence evaluation started immediately after the break-in and during the loading phase, F0 has been monitored. The steady-state was reached after about $15 \mathrm{~min}$. Moreover, once the cells were fully loaded with Fluo-4, fluorescence changes in response to different channel/receptor agonists and blockers and MPP stimulation were evaluated.

During calcium imaging experiments, we recorded membrane potential in current-clamp mode, keeping the cell at its resting membrane potential. Recorded values were displayed as an amplitude histogram, and the full width at half maximum (FWHM) was adopted as a measure of membrane potential oscillation.

\subsection{Drugs Application}

Drugs were applied to the perfusion bath or through puff apparatus, as previously described [15]. Verapamil $(20 \mu \mathrm{M})$, nickel $(100 \mu \mathrm{M}$ or $200 \mu \mathrm{M})$, TEA $(2 \mathrm{mM})$, muscimol $(10 \mu \mathrm{M})$, bicuculline methiodide (BMI, $10 \mu \mathrm{M})$, glutamate $(100 \mu \mathrm{M})$, NMDA $(300 \mu \mathrm{M})$, AP5 $(50 \mu \mathrm{M})$, CNQX $(10 \mu \mathrm{M})$ were purchased from Sigma, Italy. Paxilline $(10 \mu \mathrm{M})$ was purchased from Tocris Bioscience UK, and TTX (500 nM) from Alomone Labs, Israel.

\subsection{Statistical Analysis}

Data were expressed as mean \pm SEM. Differences between the experimental treatments were statistically evaluated by appropriately applying RM one-way ANOVA or two-way RM ANOVA followed by Tukey's posthoc test. The significance threshold was established at $p<0.05$.

Author Contributions: Conceptualization, D.L.; methodology, D.L.; formal analysis, D.L., M.D.P.; investigation, D.L.; data curation, D.L., M.D.P.; writing-original draft preparation, D.L.; writing—review and editing, P.A.; supervision, P.A.; funding acquisition, R.C. All authors have read and agreed to the published version of the manuscript.

Funding: This research received no external funding.

Conflicts of Interest: The authors declare no conflict of interest.

\section{References}

1. Gonçalves, J.T.; Schafer, S.T.; Gage, F.H. Adult Neurogenesis in the Hippocampus: From Stem Cells to Behavior. Cell 2016, 167, 897-914. [CrossRef]

2. Ambrogini, P.; Lattanzi, D.; Ciuffoli, S.; Agostini, D.; Bertini, L.; Stocchi, V.; Santi, S.; Cuppini, R. Morpho-functional characterization of neuronal cells at different stages of maturation in granule cell layer of adult rat dentate gyrus. Brain Res. 2004, 1017, 21-31. [CrossRef]

3. Dieni, C.V.; Chancey, J.H.; Overstreet-Wadiche, L.S. Dynamic functions of GABA signaling during granule cell maturation. Front. Neural Circuits 2013, 6, 11. [CrossRef]

4. Bao, H.; Asrican, B.; Li, W.; Gu, B.; Wen, Z.; Lim, S.A.; Haniff, I.; Ramakrishnan, C.; Deisseroth, K.; Philpot, B.; et al. Long-Range GABAergic Inputs Regulate Neural Stem Cell Quiescence and Control Adult Hippocampal Neurogenesis. Cell Stem Cell 2017, 21, 604-617. [CrossRef]

5. Tozuka, Y.; Fukuda, S.; Namba, T.; Seki, T.; Hisatsune, T. GABAergic excitation promotes neuronal differentiation in adult hippocampal progenitor cells. Neuron 2005, 47, 803-815. [CrossRef]

6. Ge, S.; Goh, E.L.; Sailor, K.A.; Kitabatake, Y.; Ming, G.L.; Song, H. GABA regulates synaptic integration of newly generated neurons in the adult brain. Nature 2006, 439, 589-593. [CrossRef]

7. Deshpande, A.; Bergami, M.; Ghanem, A.; Conzelmann, K.K.; Lepier, A.; Götz, M.; Berninger, B. Retrograde monosynaptic tracing reveals the temporal evolution of inputs onto new neurons in the adult dentate gyrus and olfactory bulb. Proc. Natl. Acad. Sci. USA 2013, 110, E1152-E1161. [CrossRef] 
8. Ben-Ari, Y. The GABA excitatory/inhibitory developmental sequence: A personal journey. Neuroscience 2014, 279, 187-219. [CrossRef]

9. Ambrogini, P.; Cuppini, R.; Lattanzi, D.; Ciuffoli, S.; Frontini, A.; Fanelli, M. Synaptogenesis in adult-generated hippocampal granule cells is affected by behavioral experiences. Hippocampus 2010, 20, 799-810. [CrossRef]

10. Ge, S.; Pradhan, D.A.; Ming, G.L.; Song, H. GABA sets the tempo for activity-dependent adult neurogenesis. Trends Neurosci. 2007, 30, 1-8. [CrossRef]

11. Verheugen, J.A.H.; Vijverberg, H.P.M.; Oortgiesen, M.; Cahalan, M.D. Voltage-gated and Ca2+-activated K+ channels in intact human T lymphocytes: Noninvasive measurements of membrane currents, membrane potential, and intracellular calcium. J. Gen. Physiol. 1995, 105, 765-794. [CrossRef] [PubMed]

12. Sun, H.; Luhmann, H.J.; Kilb, W. Resonance properties of different neuronal populations in the immature mouse neocortex. Eur. J. Neurosci. 2012, 36, 2753-2762. [CrossRef] [PubMed]

13. Nakaoka, Y.; Imaji, T.; Hara, M.; Hashimoto, N. Spontaneous fluctuation of the resting membrane potential in Paramecium: Amplification caused by intracellular $\mathrm{Ca}^{2+}$. J. Exp. Biol. 2009, 212, 270-276. [CrossRef]

14. Ambrogini, P.; Lattanzi, D.; Ciuffoli, S.; Betti, M.; Fanelli, M.; Cuppini, R. Physical exercise and environment exploration affect synaptogenesis in adult-generated neurons in the rat dentate gyrus: Possible role of BDNF. Brain Res. 2013, 1534, 1-12. [CrossRef]

15. Ambrogini, P.; Minelli, A.; Lattanzi, D.; Ciuffoli, S.; Fanelli, M.; Cuppini, R. Synaptically-silent immature neurons show gaba and glutamate receptor-mediated currents in adult rat dentate gyrus. Arch. Ital. Biol. 2006, 144, 115-126.

16. Wang, B.; Jaffe, D.B.; Brenner, R. Current understanding of iberiotoxin-resistant BK channels in the nervous system. Front. Physiol. 2014, 5, 382. [CrossRef]

17. Vivas, O.; Moreno, C.M.; Santana, L.F.; Hille, B. Proximal clustering between BK and CaV1.3 channels promotes functional coupling and BK channel activation at low voltage. Elife 2017, 6, e20829. [CrossRef]

18. LoTurco, J.J.; Owens, D.F.; Heath, M.J.S.; Davis, M.B.E.; Kriegstein, A.R. GABA and glutamate depolarize cortical progenitor cells and inhibit DNA synthesis. Neuron 1995, 15, 1287-1298. [CrossRef]

19. Deisseroth, K.; Singla, S.; Toda, H.; Monje, M.; Palmer, T.D.; Malenka, R.C. Excitation-neurogenesis coupling in adult neural stem/progenitor cells. Neuron 2004, 42, 535-552. [CrossRef]

20. Heigele, S.; Sultan, S.; Toni, N.; Bischofberger, J. Bidirectional GABAergic control of action potential firing in newborn hippocampal granule cells. Nat. Neurosci. 2016, 19, 263-270. [CrossRef]

21. Schmidt-Hieber, C.; Jonas, P.; Bischofberger, J. Enhanced synaptic plasticity in newly generated granule cells of the adult hippocampus. Nature 2004, 429, 184-187. [CrossRef] [PubMed]

22. Li, L.; Sultan, S.; Heigele, S.; Schmidt-Salzmann, C.; Toni, N.; Bischofberger, J. Silent synapses generate sparse and orthogonal action potential firing in adult-born hippocampal granule cells. Elife 2017, 6, e23612. [CrossRef] [PubMed]

23. Wang, B.; Rothberg, B.S.; Brenner, R. Mechanism of $\beta 4$ subunit modulation of BK channels. J. Gen. Physiol. 2006, 127, 449-465. [CrossRef] [PubMed]

24. Contreras, G.F.; Neely, A.; Alvarez, O.; Gonzalez, C.; Latorre, R. Modulation of BK channel voltage gating by different auxiliary $\beta$ subunits. Proc. Natl. Acad. Sci. USA 2012, 109, 18991-18996. [CrossRef] [PubMed]

25. Brenner, R.; Chen, Q.H.; Vilaythong, A.; Toney, G.M.; Noebels, J.L.; Aldrich, R.W. BK channel $\beta 4$ subunit reduces dentate gyrus excitability and protects against temporal lobe seizures. Nat. Neurosci. 2005, 8, 1752-1759. [CrossRef] [PubMed]

26. Stocca, G.; Schmidt-Hieber, C.; Bischofberger, J. Differential dendritic Ca2+ signalling in young and mature hippocampal granule cells. J. Physiol. 2008, 586, 3795-3811. [CrossRef] [PubMed]

27. Zhang, J.; Guan, X.; Li, Q.; Meredith, A.L.; Pan, H.L.; Yan, J. Glutamate-activated BK channel complexes formed with NMDA receptors. Proc. Natl. Acad. Sci. USA 2018, 115, E9006-E9014. [CrossRef]

28. Lohmann, C.; Wong, R.O. Regulation of dendritic growth and plasticity by local and global calcium dynamics. Cell Calcium 2005, 37, 403-409. [CrossRef]

29. Bando, Y.; Irie, K.; Shimomura, T.; Umeshima, H.; Kushida, Y.; Kengaku, M.; Fujiyoshi, Y.; Hirano, T.; Tagawa, Y. Control of Spontaneous Ca2+ Transients Is Critical for Neuronal Maturation in the Developing Neocortex. Cereb. Cortex 2016, 26, 106-117. [CrossRef]

30. Horigane, S.I.; Ozawa, Y.; Yamada, H.; Takemoto-Kimura, S. Calcium signalling: A key regulator of neuronal migration. J. Biochem. 2019, 165, 401-409. [CrossRef] 
31. Ambrogini, P.; Cuppini, R.; Cuppini, C.; Ciaroni, S.; Cecchini, T.; Ferri, P.; Sartini, S.; Del Grande, P. Spatial learning affects immature granule cell survival in adult rat dentate gyrus. Neurosci. Lett. 2000, 286, 21-24. [CrossRef]

32. Pedroni, A.; Minh, D.D.; Mallamaci, A.; Cherubini, E. Electrophysiological characterization of granule cells in the dentate gyrus immediately after birth. Front. Cell. Neurosci. 2014, 8, 44. [CrossRef] [PubMed]

33. Lattanzi, D.; Savelli, D.; Di Palma, M.; Sartini, S.; Eusebi, S.; Borroto-Escuela, D.O.; Cuppini, R.; Fuxe, K.; Ambrogini, P. Electrophysiological approach to GPCR-RTK interaction study in hippocampus of adult rats. Neuromethods 2018, 140, 71-90.

34. Sartini, S.; Lattanzi, D.; Di Palma, M.; Savelli, D.; Eusebi, S.; Sestili, P.; Cuppini, R.; Ambrogini, P. Maternal Creatine Supplementation Positively Affects Male Rat Hippocampal Synaptic Plasticity in Adult Offspring. Nutrients 2019, 11, 2014. [CrossRef]

(C) 2020 by the authors. Licensee MDPI, Basel, Switzerland. This article is an open access article distributed under the terms and conditions of the Creative Commons Attribution (CC BY) license (http://creativecommons.org/licenses/by/4.0/). 